this affect the satisfactory implementation of health services to all parts of Slovenia and the healthy adults are not interested in the other alternative forms of care at the end of life.

\section{P 087 KNOWLEDGE AND EXPERIENCE WITH HOSPICE AND PALLIATIVE CARE IN SLOVENIA AMONG HEALTHY ADULTS}

Albina Bobnar. Faculty of health Sciences, University Ljubljana, Ljubljana, Slovenia

10.1136/bmjspcare-2014-000654.128

Background In Slovenia we started with the process of working and informing the public about palliative care as an integral part of the health care system after 2003, in preparation for entry into the European Union. The National Palliative Care Program was published in 2010. For the patients and relatives had organized palliative care in the same year in two hospitals and hospice care in one Hospice house. Due to the lack of palliative services, very few people involved in hospice or palliative care.

Aim The aim of this study was to identify differences between healthy adults' knowledge of and experience with hospice and palliative care.

Methods In the academic year 2010/2011, students of nursing to do interviews with 695 healthy adults. Bivariate analysis were made to determine statistically significant differences among healthy adults about the knowledge and experience with hospice and palliative care regarding of gender, age, place of residence, employment status, education, marital status.

Results Among the 59,4\% women and 40,6\% of men aged 18-59 years $(56,3 \%)$ and $43,7 \%$ of those aged $>60$ years, living in the city $(49,9 \%)$ and villages $(51,1 \%)$, the women in the younger age group who live in the city, better known hospice and palliative care. Greater knowledge among employees $(47,6 \%)$ and participants with education $>13$ years (21\%). Marital status does not affect their knowledge of hospice and palliative care, as well as no differences in experience with this type of care among healthy adults.

Conclusion The healthy adults know little about hospice and palliative care, much less they have experience in this field. Might on 